\title{
Análise de dois métodos de desinfecção de condutos radiculares após preparo para pinos: proposta de protocolo protético: estudo in vitro
}

\author{
Analysis of two methods of root canal disinfection after preparation for pins: proposal of prosthetic \\ protocol: in vitro study
}

Isaac José Peixoto Batinga ROCHA ${ }^{\text {ał}, ~ L e t i ́ c i a ~ D e l ~ R i o ~ S I L V A ~}{ }^{a}$, Sybelle Lopes de SANTA MARIAa, Daniel Pinto de OLIVEIRA ${ }^{\mathrm{a}}$, Zenaldo PORFÍRIO ${ }^{\mathrm{b}}$

${ }^{a}$ Faculdade de Odontologia de Alagoas, UFAL - Universidade Federal de Alagoas, Maceió, AL, Brasil

'Instituto de Ciências Biológicas, UFAL - Universidade Federal de Alagoas, Maceió, AL, Brasil

\begin{abstract}
Resumo
Introdução: Quando existe perda de suporte coronário e ainda desgaste adicional devido a tratamento endodôntico, muitas vezes, é necessária a utilização de um retentor intrarradicular que devolva a retenção para a restauração, reestabelecendo estética e função às estruturas dentárias perdidas. A cadeia asséptica mantida durante a endodontia pode ser quebrada com alguns procedimentos clínicos. Objetivo: Testar um protocolo de desinfecção por E. faecalis dos condutos radiculares, nas etapas de confecção de um retentor intrarradicular, desmistificando que a quebra da cadeia asséptica e o surgimento de infecções radiculares sejam provenientes da reabilitação protética. Material e método: 50 dentes unirradiculares com endodontia concluída foram desobturados, tiveram seus condutos preparados para retentor intrarradicular e foram contaminados por Enterococcus faecalis. Os dentes foram separados em três grupos de acordo com a substância desinfectante: G1-solução fisiológica (n=10), G2- hipoclorito de sódio 2,5\% $(\mathrm{n}=20), \mathrm{G} 3$ - clorexidina $2 \%(\mathrm{n}=20)$. Em seguida, foi feita a desinfecção do conduto, secagem e análise da eficácia da solução. A avaliação da presença da bactéria foi feita através do cultivo em caldo Brain Heart Infusion, pelo método da turvação, e posterior identificação pelo meio Ágar Bílis-Esculina. A análise estatística foi feita pelo método do quiquadrado em tabulação cruzada, onde $p<0,0001$. Resultado: Observou-se a inibição bacteriana de $100 \% \mathrm{em}$ G2 e G3 e crescimento bacteriano de 100\% em G1. Conclusão: O emprego das substâncias avaliadas nas etapas protéticas de finalização de um retentor intrarradicular, como protocolado por esta pesquisa, é capaz de manter a cadeia asséptica sem interferir no sucesso da reabilitação protética.
\end{abstract}

Descritores: Enterococcus faecalis; prótese dentária; pinos dentários; clorexidina; hipoclorito de sódio.

\begin{abstract}
Introduction: When there is loss of the coronary supports and still further wear due to endodontic treatment, very often, it is necessary to use a intraradical retainer to restore aesthetics and function of lost dental structures. Within this rehabilitation, the aseptic chain which was maintained during endodontics can be broken using some clinical procedures. Aim: Test a disinfection protocol by $E$. faecalis of root canals, in the steps of making an intraradicular retainer, demystifying that the fracture of the aseptic chain and the emergence of root infections are coming from prosthetic rehabilitation. Materials and method: 50 single-rooted teeth with complete endodontics were unfilled, they had their conduits prepared for an intraradical retainer and contaminated by Enterococcus. faecalis. The teeth were divided into 3 groups according to the disinfectant solution. G1- saline ( $\mathrm{n}=10), \mathrm{G} 22.5 \%$ sodium hypochlorite $(n=20)$, G3- chlorhexidine $2 \%(n=20)$. Then, a disinfection of conduit, drying and analysis of the efficacy of the solution was made. The evaluation of the presence of Enterococcus faecalis was made by cultivating in Brain Heart Infusion broth by the method of turbidity, and subsequent identification by means Agar Bile-Esculin. Statistical analysis were performed using the chi-square method in cross-tabulation, where $\mathrm{p}<0.0001$. Result: As a result, it was observed 100\% bacteria inhibition in G2 and G3, and bacterial growth of 100\% in G1. Conclusion: The use of substances assessed in the prosthetic stages of finalizing an intraradical retainer, as filed by this research, is able to maintain the aseptic chain without interfering with success of prosthetic rehabilitation.
\end{abstract}

Descriptors: Enterococcus faecalis; dental prosthesis; dental pins; chlorhexidine; sodium hypochlorite. 


\section{INTRODUÇÃO}

Quando ocorre uma perda estrutural muito extensa, se faz necessária a utilização de retenção intrarradicular e uma prótese unitária que restabeleçam a estética e a função ${ }^{1,2}$. A utilização de retentor intrarradicular (RIR) tem por finalidade propiciar condições adequadas de retenção para que a reabilitação oral seja executada com eficiência e assim não haja nenhum transtorno futuro para as funções mastigatórias ${ }^{1,3,4}$

É fundamental ter um preparo intrarradicular em que se preserve a estrutura da raiz, bem como as estruturas subjacentes e periapicais, pois o sucesso da prótese dependerá de que cada procedimento seja efetuado dentro das normas e técnicas predeterminadas. É evidente que a terapia endodôntica bem-sucedida é um pré-requisito para indicação de um RIR ${ }^{2}$.

Vários estudos sugerem que, durante o preparo do conduto radicular, a preservação de 3 a $5 \mathrm{~mm}$ de guta-percha (Dentsply Maillefer, Ballaigues, Switzerland), que é o principal material obturador do espaço radicular, deve ser mantida para que haja uma manutenção do selamento apical ${ }^{4-8}$.

Muitas são as modalidades de bactérias encontradas colonizando os canais radiculares infectados, sendo a maioria anaeróbia estrita, gênero cujas espécies mais comuns são Actinomyces; Pseudoramibacter; Eubacterium; Peptostreptococcus; Treponema. Já no grupo das aeróbias, temos a Pseudomonas aeruginosa; quando nos referimos às anaeróbias facultativas, podemos citar o Streptococcus e o Enterococcus faecalis ${ }^{1,9}$.

Os E. faecalis são cocos facultativos anaeróbios Gram-positivos, responsáveis por cerca de 80 a 90\% de infecções enterecocais em humanos, sendo considerados os microrganismos mais encontrados em dentes com infecções pós-tratamento endodôntico ${ }^{9}$. Grande parte dos casos clínicos mostra canais radiculares infectados com $E$. faecalis que permanecem assintomáticos por anos, pois não responderam à terapia endodôntica convencional ${ }^{9,10}$.

Diversos trabalhos apontam que falhas no tratamento endodôntico ou durante a confecção do RIR ocorrem em virtude de trabalhos realizados sem a observação dos princípios biológicos ${ }^{1,5,9}$. Logo, existe uma preocupação com a manutenção da cadeia asséptica observada, tanto no tratamento endodôntico como nos procedimentos que compreendem a confecção dos RIRs ${ }^{5}$.

Durante a prática clínica do preparo do conduto e a cimentação de um retentor intrarradicular, existe um período crítico em virtude dos comuns acidentes nos procedimentos de desobturação, preparo do canal, moldagem, cimentação do retentor intrarradicular e nos intervalos entre as sessões, o que pode ocasionar a recontaminação dos canais radiculares ${ }^{1}$.

Com o intuito de manter a cadeia asséptica do canal, propostas como soluções irrigantes são importantes no preparo do conduto, pois auxiliam na limpeza e lubrificação do canal radicular, eliminação dos detritos, além de apresentarem efeito antimicrobiano, sem prejuízo para a região periapical ${ }^{11,12}$.

A seleção de um irrigante ideal depende de sua ação sobre os micro-organismos e tecidos periapicais. As substâncias químicas auxiliares mais populares e mais usadas são o Hipoclorito de Sódio $(\mathrm{NaOCl})$ e o Digluconato de Clorexidina $(\mathrm{CHX})^{11-14}$.
A literatura demonstra vários guias de padronização criados para as etapas de desinfecção no tratamento endodôntico, os quais avaliam as soluções de $\mathrm{NaOCl}$ e $\mathrm{CHX}$ em várias concentrações distintas, volumes e tempos de exposição.

Portanto, a presente pesquisa teve como objetivo testar o protocolo de desinfecção por E. faecalis dos condutos radiculares, já utilizado pela endodontia, nas etapas de confecção de um retentor intrarradicular, desmistificando que a quebra da cadeia asséptica e o surgimento de infecções radiculares sejam provenientes da reabilitação protética.

A hipótese testada é que não há quebra da cadeia asséptica durante a reabilitação protética de dentes tratados endodonticamente.

\section{MATERIAL E MÉTODO}

\section{Amostra}

A avaliação experimental foi baseada na desinfecção de condutos radiculares de dentes humanos após a preparação para confecção de RIR. Os elementos dentais foram doados pelo Banco de Dentes Humanos da Faculdade de Odontologia de Alagoas (FOUFAL) para o Laboratório de Endodontia da mesma faculdade e, posteriormente, cedidos para a presente pesquisa.

Convencionou-se a quantidade de 50 dentes unirradiculares, com o tratamento endodôntico concluído através da Técnica Coroa-Ápice da FOUFAL, sendo excluídos os dentes multirradiculares, que não possuíam tratamento endodôntico, ou que a qualidade da obturação fosse insatisfatória.

\section{Preparo do Conduto}

Os dentes foram numerados e radiografados individualmente e, através de uma régua milimetrada, a medida do canal foi aferida para que o selamento apical fosse respeitado. Os parâmetros aferidos foram delimitados pelo comprimento aparente do dente, o qual é medido do ápice radicular até a porção mais coronária do elemento.

Posteriormente, o preparo do conduto radicular seguiu procedimentos de desobturação. Foram utilizadas brocas tipo Gattes-Glidden (Dentsply Maillefer Ballaigues, Switzerland) de números 5,4,3 e brocas Largo (Dentsply Maillefer Ballaigues, Switzerland) de numeração 3 e 2 numa sequência decrescente de calibre, respeitando o limite do selamento apical de $5 \mathrm{~mm}$. Em seguida, os dentes foram submetidos à esterilização em autoclave através do calor úmido sob pressão (Luferco, Araraquara, Brasil).

Depois da desobturação dos condutos, foram feitas novas radiografias. Foi utilizada uma peça reta, micromotor e um disco de carborundum, para separar a coroa da raiz no limite amelocementário.

\section{Preparo do Inóculo}

Dando sequência ao estudo e de acordo com normas do laboratório de microbiologia do Centro de Patologia e Medicina Laboratorial da Universidade Estadual de Ciências da Saúde de Alagoas (Uncisal), foram utilizados os equipamentos e soluções necessárias ao cultivo do E. faecalis (ATCC29212). 
A etapa laboratorial foi semelhante a diversas metodologias revisadas $^{11,15}$, como a utilização de meios de cultura e semeio bacteriano e a padronização do ambiente, tempo e temperatura na estufa. O caldo BHI foi utilizado como meio para cultivo de micro-organismos. Possuía cor original amarelo-clara, e a presença de turvação afirma o crescimento bacteriano na solução ${ }^{6}$. Iniciou-se com o preparo do caldo BHI com micro-organismos (E. feacalis) vivos, onde os espécimes foram inoculados com uma suspensão correspondente à concentração bacteriana em escala 0.5 de Mcfarland $\left(1,5 \times 10^{8} \mathrm{UFC} / \mathrm{ml}\right.$ - Unidades Formadoras de Colônias), permanecendo por 24 horas na estufa a $37^{\circ} \mathrm{C}$ para a confirmação qualitativa das bactérias através do turvamento ${ }^{7,16}$.

Em seguida, houve o semeio na Placa de Petri em Ágar Sangue (AS), seguido de mais um período de 24 horas dentro da estufa a $37^{\circ} \mathrm{C}$, onde se obteve a proliferação bacteriana e surgimento das $\mathrm{UFCs}^{14}$.

Através do semeio em AS, uma nova suspensão em solução salina tamponada, que mantém a bactéria viável, foi criada para posterior contaminação dos condutos radiculares, ficando por mais 24 horas na estufa.

\section{Contaminação/Desinfecção}

Esta etapa foi dividida em três grupos, sendo um grupo controle para a solução de Soro fisiológico (G1 - dez remanescentes radiculares) e dois experimentais para as soluções de $\mathrm{NaOCl}$ a 2,5\% (G2 - vinte remanescentes radiculares) e CHX a 2\% (G3 - vinte remanescentes radiculares). O protocolo de desinfecção escolhido foi seguido pelos três grupos, havendo apenas a mudança nas soluções de irrigação (Soro fisiológico, $\mathrm{NaOCl}$ a 2,5\% e CHX a 2\%), sendo respeitado o controle da biossegurança para que não ocorresse contaminação cruzada entre as etapas.
Com o auxílio de um cone de papel e uma pinça, a suspensão bacteriana foi coletada e introduzida nos condutos na sequência numérica dos remanescentes radiculares, seguida de fechamento com material vedante (Coltosol - Vigodent, Rio de Janeiro, Rio de Janeiro, Brasil) e manutenção na estufa a $37^{\circ} \mathrm{C}$ por 30 minutos em uma bandeja umidificada com gaze e SF, simulando assim as condições ambientais presentes na cavidade bucal ${ }^{9}$. Depois da retirada dos dentes da estufa, removeu-se o material vedante e o cone de papel contaminado.

Através de seringa e agulha, os condutos radiculares foram individualmente irrigados com $5 \mathrm{~mL}$ da solução controle e deixados inundados por 5 minutos, sendo secos, em seguida, com cones de papel.

\section{Controle da Efetividade}

A verificação da efetividade desinfetante da solução foi feita introduzindo outro cone de papel seco no interior do conduto, vedado novamente com Coltosol e armazenado na estufa por aproximadamente 30 minutos. Em seguida, retirou-se o cone de papel para depositá-lo dentro de tubos de ensaio contendo caldo $\mathrm{BHI}$ para o retorno à estufa por mais 24 horas.

A leitura do caldo BHI, para observar se houve desinfecção dos condutos radiculares, foi feita através da observação da turvação da solução (Figura 1 - G1: grupo controle com 100\% das amostras apresentando turvamento). A avaliação da presença de E. feacalis no cone de papel foi feita através do método de identificação, utilizando o meio Ágar Bílis-Esculina (Figura 2 - Método de identificação de E. faecalis: Bílis-Esculina através do enegrecimento), o qual é baseado na capacidade de algumas bactérias hidrolisarem esculina em presença de bílis. As bactérias que nela conseguem crescer formam um complexo enegrecido através dos íons férricos da solução $0^{5,17}$. (Figura 3 - Organograma Metodológico).

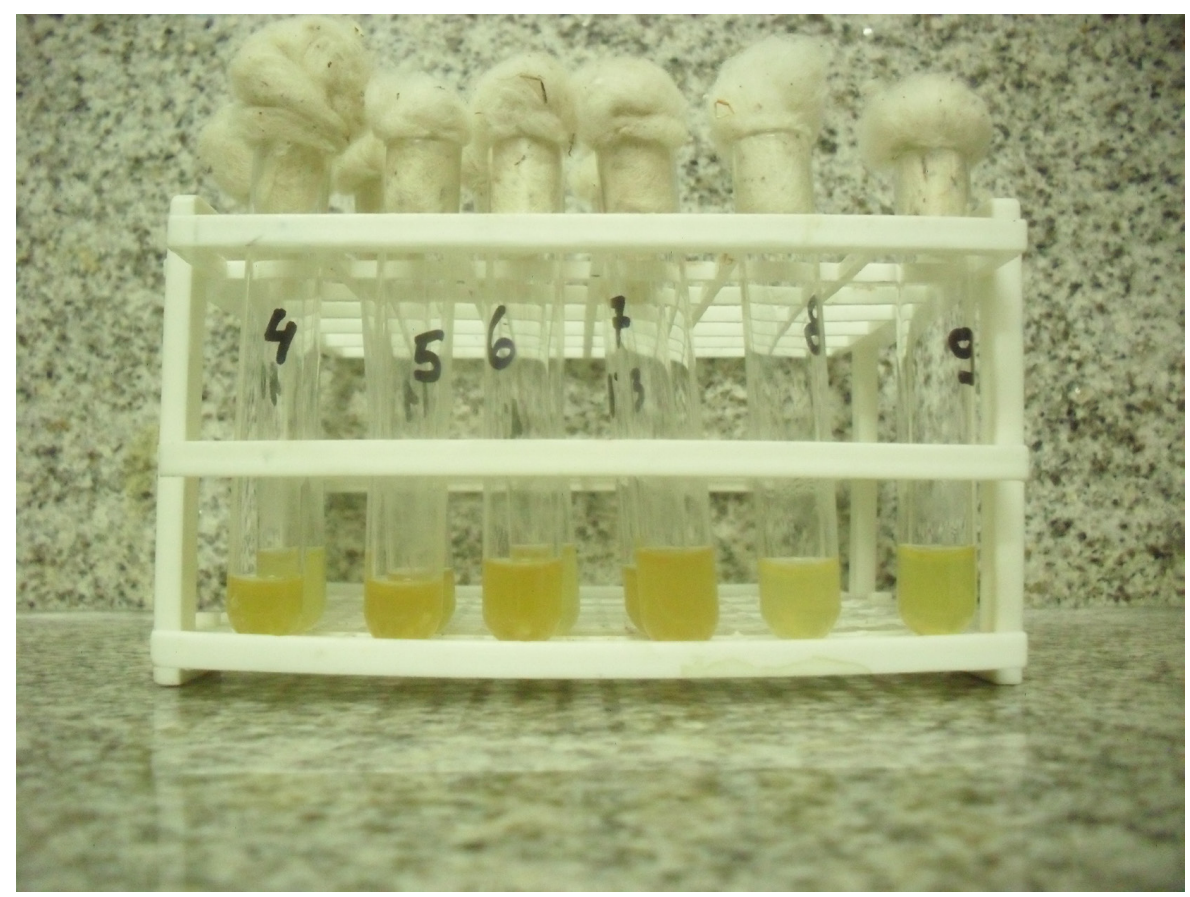

Figura 1. G1 (grupo controle) com 100\% das amostras apresentando turvamento. 


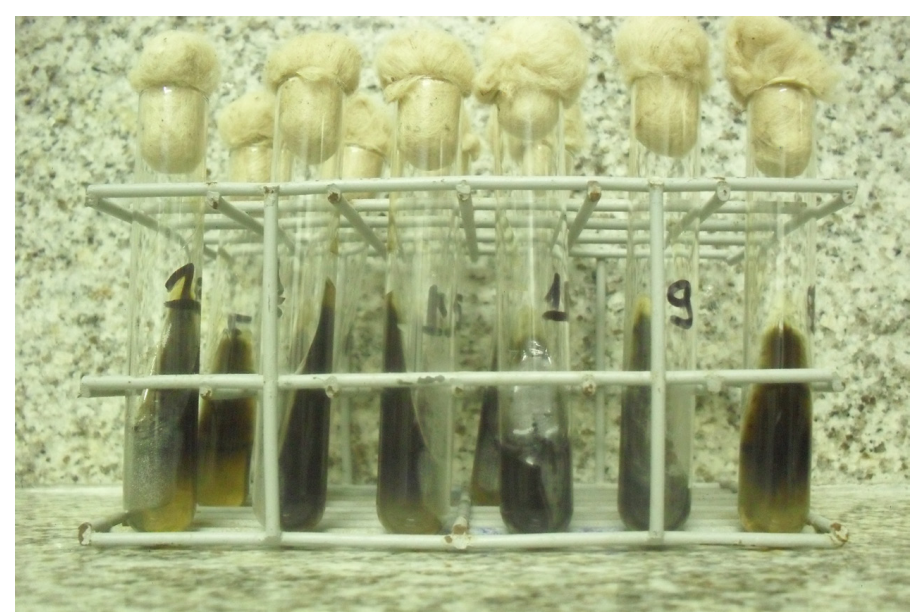

Figura 2. Método de identificação de E. faecalis (Bílis-Esculina) através do enegrecimento.

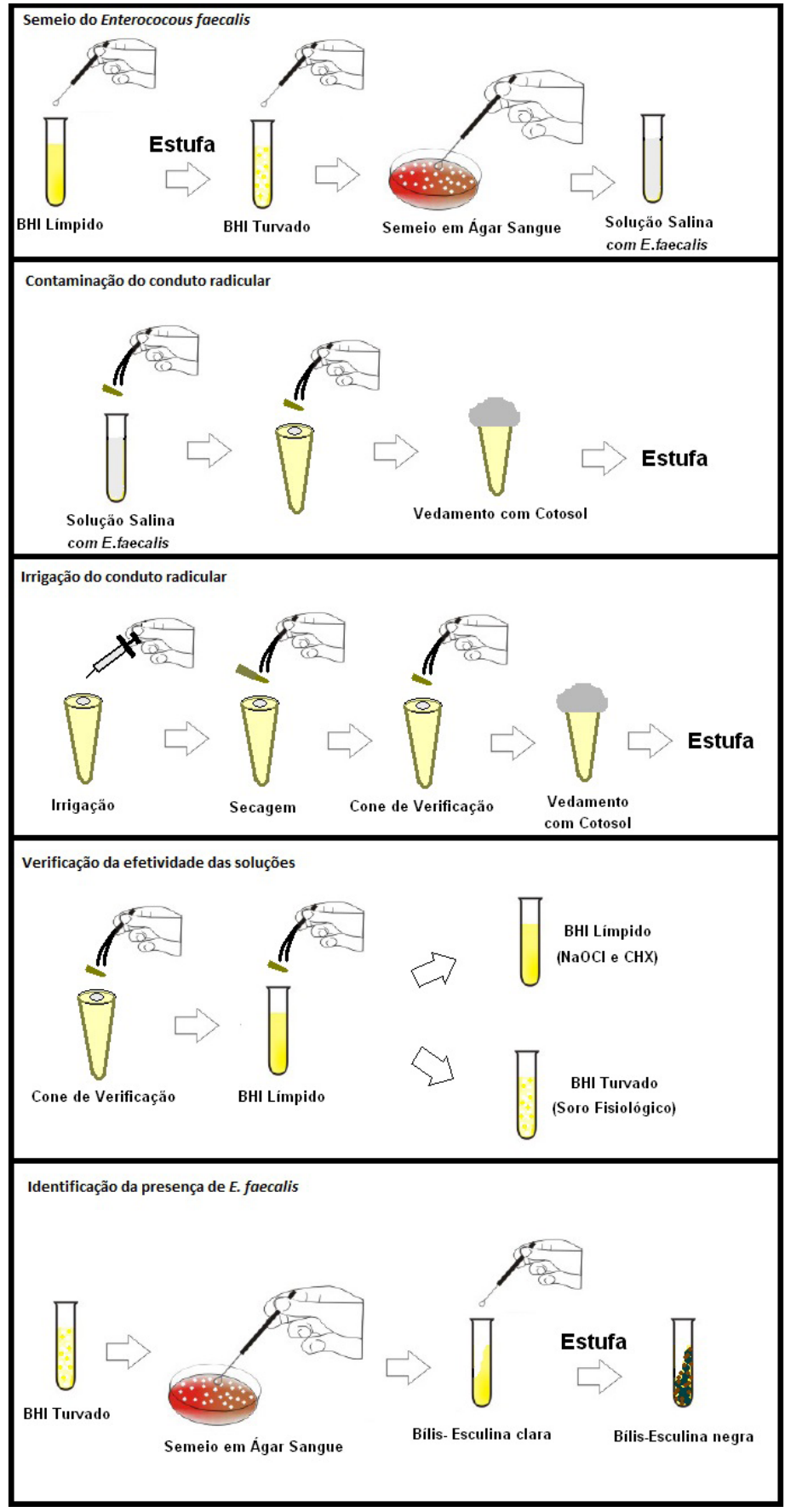

Figura 3. Organograma metodológico. 
Tabela 1. Presença ou ausência de turvamento em BHI após desinfecção dos condutos preparados de acordo com cada grupo

\begin{tabular}{cccc}
\hline \multirow{2}{*}{ Grupo } & \multicolumn{3}{c}{ Cultivo/Turvamento } \\
\cline { 2 - 4 } & $(\%) \mathbf{n}(+)$ & $(\%) \mathbf{n}(-)$ & $\boldsymbol{p}$-valor \\
\hline G1 & 100 & 0 & $0,001^{*}$ \\
G2 & 0 & 100 & $0,001^{*}$ \\
G3 & 0 & 100 & $0,001^{\star}$ \\
\hline
\end{tabular}

${ }^{\star}$ Quiquadrado $=50,000 ; \alpha=1 \%$.

\section{Analise Estatística}

Os dados foram tabulados em planilha eletrônica e os resultados obtidos nos grupos, analisados no que se refere à significância estatística, pelo teste método do quiquadrado com uma significância de $1 \%$. Os valores obtidos foram absolutos e dentro do esperado para o processo de contaminação/desinfecção.

\section{RESULTADO}

Todas as amostras de um mesmo grupo tiveram o mesmo comportamento, comprovando a ausência de contaminação cruzada e falhas durante a pesquisa. Em G1, as 10 amostras apresentaram turvação em meio BHI. Os grupos G2 e G3 não apresentaram o turvamento das soluções, evidenciando o potencial desinfetante em $100 \%$ dos casos tanto no $\mathrm{NaOCl}$ como na CHX. (Tabela 1: Presença ou ausência de turvamento em BHI após desinfecção dos condutos preparados de acordo com cada grupo).

\section{DISCUSSÃO}

Os autores afirmam ${ }^{1,9,11}$ que a reabilitação de um elemento dentário vai além do término do tratamento endodôntico. Mesmo diante de uma variedade de técnicas e materiais para restauração coronária dos dentes endodonticamente tratados, o RIR muitas vezes continua sendo necessário ${ }^{3}$. O tempo ideal para o preparo intrarradicular após a conclusão do tratamento endodôntico seria de 21 dias, pois, após este período, o dente fornece melhor força de adesão, comparado a preparos realizados logo após o preenchimento do canal com material obturador ${ }^{18}$.

Neste intervalo entre o preparo e a cimentação do RIR, pode haver quebra da cadeia asséptica e recontaminação dos canais radiculares $^{1,5,9,11-14}$. Diversos trabalhos ${ }^{1,3,9}$ apontam que falhas no tratamento endodôntico ou durante a confecção do RIR ocorrem em virtude de trabalhos realizados sem a observação dos princípios biológicos.

Estudos demonstram a efetividade das soluções experimentais de $\mathrm{NaOCl}$ e CHX na endodontia durante a desinfecção dos condutos radiculares. E, diante das variadas concentrações, volumes e tempos de exposição, convencionou-se adotar parâmetros clínicos de fácil acesso ao profissional protesista para que a fase de preparo do conduto para receber um RIR seja realizada sem a quebra da cadeia asséptica.
É possível observar que a concentração e o tempo de exposição das soluções desinfetantes usadas nos condutos radiculares são essenciais no resultado da eliminação bacteriana. E, dentre as substâncias desinfetantes de maior uso no consultório odontológico, estão o $\mathrm{NaOCl}$ e a CHX ${ }^{1,10,11,15}$.

Vários são os autores que entram em concordância com este trabalho no que se refere à utilização das soluções $\mathrm{NaOCl}$ e CHX como inibidoras da atividade microbiana do E. faecalis ${ }^{11,14,15}$. Fato esse também confirmado através de microscopia confocal que evidenciou que a associação de $\mathrm{NaOCl}$ e $\mathrm{CHX}$ demonstra maior efetividade contra bactérias, devido à ação conjunta de dissolução de tecidos orgânicos, atividade bactericida e substantividade ${ }^{19}$.

Paradella et al. ${ }^{9}$ afirmam que não há diferenças significantes em termos de redução de unidades formadoras de colônia de E. faecalis comparando-se clorexidina em gel a $2 \%$, clorexidina líquida a $2 \%$ e hipoclorito de sódio a 5,25\%. Técnicas eficientes de irrigação com o uso de $\mathrm{CHX} 2 \%$ e do $\mathrm{NaOCl}$ são métodos confiáveis para combater o $E$. faecalis do sistema de canais radiculares e reduzir o insucesso do tratamento endodôntico ${ }^{20}$.

Zamany et al. ${ }^{21}$ demonstram que a CHX a $2 \%$ maximiza a desifecção dos condutos quando adicionada após a convencional instrumentação mecânica com $\mathrm{NaOCl}$ a $1 \%$, entrando em conflito com Basrani et al. ${ }^{13}$, que reforçam que o uso concomitante das duas substâncias deve ser evitado pois resulta na formação de um precipitado, devendo-se remover o $\mathrm{NaOCl}$ antes da colocação do CHX no canal. Vale ainda ressaltar que a CHX, quando usada para pré-tratamento de superficie do canal radicular pré utilização de pinos de fibra de vidro incrementados com resina composta, demonstrou efeitos positivos na preservação da resistência de união e na durabilidade da adesão desses pinos, tanto a curto (24 horas) quanto a longo prazo (1 ano $)^{22}$.

Foi evidenciada também a influência do $\mathrm{NaOCl}(1,0 \%, 2,5 \%$, $5,25 \%)$ e da CHX Gel (2\%) como agentes irrigantes na resistência à tração de um sistema adesivo usado para cimentar pinos de fibra de vidro em dentina radicular e nenhuma diferença significativa foi encontrada ${ }^{16}$. A associação do $\mathrm{NaOCl}$ com EDTA 17\% também não interveio na força de adesão de pinos de fibra de vidro em dentina radicular ${ }^{23}$.

A presente pesquisa, em concordância com os artigos revisados, fez uso de diferentes soluções $(\mathrm{NaOCl}$ a 2,5\%, CHX a 2\% e Soro Fisiológico), padronizando o volume e o tempo de irrigação em $5 \mathrm{ml}$ e 5 minutos, respectivamente, o que resultou na quebra do ciclo microbiológico do E. faecalis dentro do conduto preparado proteticamente.

Contudo novas pesquisas devem ser feitas no intuito de tornar mais acessível e prática a utilização pelo clínico, como a criação de um protocolo que utilize soluções com menores concentrações e diminuindo o tempo de irrigação.

\section{CONCLUSÃO}

O protocolo de desinfecção utilizado, preconizando irrigação com $5 \mathrm{ml}$ das soluções de $\mathrm{NaOCl}$ a 2,5\% e CHX a $2 \%$ e permanência no conduto por um período de 5 minutos, foi suficiente para demonstrar a atividade contra Enterococcus faecalis e a possibilidade de empregá-las nas etapas protéticas de finalização de um RIR (desobturação, preparo, moldagem e cimentação dos condutos). 


\section{REFERÊNCIAS}

1. Castro KS, Batista AUD, D’Assunção FLC, Formiga ALN Fo, Oliveira JFCD. Avaliação dos cuidados assépticos durante a confecção do preparo para retentor intra radicular por endodontistas e protesistas de João Pessoa - PB. Rev Fac Odontol Univ Fed Bahia. 2010;40:7-16.

2. Souza EM, Pappen FG, Leonardi DP, Flores VO, Berbert FLCV. O papel da anatomia radicular na colocação de pinos pré-fabricados: uma visão endodôntica. Rev Gaúcha Odontol. 2007 Jan-Mar;55(1):77-82.

3. Clavijo RGV, Souza NC, Andrade MF, Susin AH. Pinos anatômicos: uma nova perspectiva clínica. Rev Dental Press Estét. 2006 JulSet;3(3):100-21.

4. Mazaro JVQ, Assunção WG, Rocha EP, Zuim PRJ, Gennari H Fo. Fatores determinantes na seleção de pinos intra-radiculares. Rev Odontol UNESP. 2006 Out-Dez;35(4):223-31.

5. Mozini ACA, Vansan LP, Sousa MD No, Pietro R. Influence of the length of remaining root canal filling and post space preparation on the coronal leakage of Enterococcus faecalis. Braz J Microbiol. 2009 Mar;40(1):174-9. PMid:24031339. http://dx.doi.org/10.1590/S151783822009000100030 .

6. Lima RMN, Nunes E, Silveira FF. Comparação do selamento apical após obturação dos canais com os sistemas guta-percha / AH26 ${ }^{\circledR}$ e Resilon / Epiphany ${ }^{\oplus}$. RFO UPF. 2007 Set-Dez;12(3):56-60.

7. Maranhão KM, Klautau EK, Lamarão SMS. Estudo in vitro da infiltração coronária em selamentos endodônticos provisórios. Rev Odontol UNESP. 2007 Jan-Mar;36(1):91-6.

8. Zaia AA, Nakagawa R, Quadros I, Gomes BPFA, Ferraz CCR, Teixeira FB, et al. An in vitro evaluation of four materials as barriers to coronal microleakage in root-filled teeth. Int Endod J. 2002 Sep;35(9):729-34. PMid:12449022. http://dx.doi.org/10.1046/j.1365-2591.2002.00529.x.

9. Paradella TC, Koga-Ito CY, Jorge AOC. Enterococcus faecalis: considerações clínicas e microbiológicas. Rev Odontol UNESP. 2007 AbrJun;36(2):163-8.

10. Sebeen M, Boopathy T. Enterococcus faecalis: an endodontic challenge. JIADSR. 2011:33-7.

11. Estrela C, Ribeiro RG, Estrela CR, Pécora JD, Sousa-Neto MD. Antimicrobial effect of $2 \%$ sodium hypochlorite and $2 \%$ chlorhexidine tested by different methods. Braz Dent J. 2003;14(1):58-62. PMid:12656467. http://dx.doi.org/10.1590/S0103-64402003000100011.

12. Estrela C, Silva JA, Alencar AHG, Leles CR, Decurcio DA. Efficacy of sodium hypochlorite and chlorhexidine against enterococcus faecalis: a systematic review. J Appl Oral Sci. 2008 Nov-Dec;16(6):364-8. PMid:19082392. http://dx.doi.org/10.1590/S1678-77572008000600002.

13. Basrani BR, Manek S, Sodhi RN, Fillery E, Manzur A. Interaction between sodium hypochlorite and chlorhexidine gluconate. J Endod. 2007 Aug;33(8):966-9. PMid:17878084. http://dx.doi.org/10.1016/j.joen.2007.04.001.

14. Sena NT, Gomes BP, Vianna ME, Berber VB, Zaia AA, Ferraz CC, et al. In vitro antimicrobial activity of sodium hypochlorite and chlorhexidine against selected single-species biofilms. Int Endod J. 2006 Nov;39(11):878-85. PMid:17014526. http://dx.doi.org/10.1111/j.13652591.2006.01161.x.

15. Karale R, Thakore A, Shetty V. An evaluation of antibacterial efficacy of 3\% sodium hypochlorite, high-frequency alternating current and $2 \%$ chlorhexidine on Enterococcus faecalis: an in vitro study. J Conserv Dent. 2011 Jan;14(1):2-5. PMid:21691496. http://dx.doi.org/10.4103/09720707.80721 .

16. Pelegrine RA, De Martin AS, Cunha RS, Pelegrine AA, Bueno CES. Influence of chemical irrigants on the tensile bond strength of an adhesive system used to cement glass fiber posts to root dentin. Oral Surg Oral Med Oral Pathol Oral Radiol Endod. 2010 Nov;110(5):e73-6. PMid:20813561. http://dx.doi.org/10.1016/j.tripleo.2010.05.005.

17. Brasil. Ministério da Saúde. Agência Nacional de Vigilância Sanitária - ANVISA. Manual de microbiologia clínica para o controle de infecção em serviços e saúde: descrição dos meios de cultura empregados nos exames microbiológicos. Módulo IV. Brasília: ANVISA; 2004.

18. Machado MB, Alves Morgan LF, Gomes GM, Vasconcellos WA, Cardoso FP, Albuquerque RC. Effects of immediate and delayed intraradicular preparation on bond strength of fiber posts. Indian J Dent Res. 2015 May-Jun;26(3):244-7. PMid:26275188. http://dx.doi.org/10.4103/09709290.162879 .

19. Flach N, Bottcher DE, Parolo CC, Firmino LB, Malt M, Lammers ML, et al. Confocal microscopy evaluation of the effect of irrigants on Enterococcus faecalis biofilm: an in vitro study. Scanning. 2016 Jan-Feb;38(1):57-62. PMid:26153228. http://dx.doi.org/10.1002/sca.21241.

20. Stuart C, Schwartz S, Beeson T, Owatz C. Enterococcus faecalis: its role in root canal treatment failure and current concepts in retreatment. J Endod. 2006 Feb;32(2):93-8. PMid:16427453. http://dx.doi.org/10.1016/j.joen.2005.10.049.

21. Zamany A, Safavi K, Spångberg LSW. The effect of chlorhexidine as an endodontic disinfectant. Oral Surg Oral Med Oral Pathol Oral Radiol Endod. 2003 Nov;96(5):578-81. PMid:14600693. http://dx.doi.org/10.1016/S1079-2104(03)00168-9.

22. Cecchin D, de Almeida JF, Gomes BP, Zaia AA, Ferraz CC. Influence of chlorhexidine and ethanol on the bond strength and durability of the adhesion of the fiber posts to root dentin using a total etching adhesive system. J Endod. 2011 Sep;37(9):1310-5. PMid:21846556. http:// dx.doi.org/10.1016/j.joen.2011.05.004.

23. Renovato SR, Santana FR, Ferreira JM, Souza JB, Soares CJ, Estrela C. Effect of calcium hydroxide and endodontic irrigants on fibre post bond strength to root canal dentine. Int Endod J. 2013 Aug;46(8):738-46. PMid:23551247. http://dx.doi.org/10.1111/iej.12053.

\section{CONFLITOS DE INTERESSE}

Os autores declaram não haver conflitos de interesse. 


\section{*AUTOR PARA CORRESPONDÊNCIA}

Isaac José Peixoto Batinga Rocha, Faculdade de Odontologia de Alagoas, UFAL - Universidade Federal de Alagoas, Rua Prefeito Abdon Arroxelas, 58, Apartamento 801, Ponta Verde, 57035-380 Maceió - AL, Brasil, e-mail: isaacbatinga@gmail.com

Recebido: Fevereiro 2, 2017 Aprovado: Abril 11, 2017 